\title{
The effect of using synthetic fibers on some properties of modified juss
}

\author{
Nada Mahdi Fawzi ${ }^{1, *}$, Luma Abdul Ghani Zghair ${ }^{2}$, Hind Hussein Hamad ${ }^{3}$ \\ ${ }^{1}$ College of Engineering, Baghdad University , Baghdad, Iraq \\ ${ }^{2}$ Civil Engineering Department, Al- Mustansiriyah University, Baghdad, Iraq \\ ${ }^{3}$ College of physical education and sports science, Baghdad University, Baghdad, Iraq
}

\begin{abstract}
This paper examines the mechanical properties of a composite material made of modified Iraqi gypsum (juss) reinforced with polypropylene fibers. The modified juss was prepared by adding two percentages of cement $(5,10) \%$. Two percentages of polypropylene fibers were used, to reinforce the modified juss $(1,2) \%$. The water/dry compound ratio used was equal to $0.53 \%$. The composite was evaluated based on compressive strength, flexural strengths, absorption percentage, density, acoustic impedance, ultra - pulse velocity, longitudinal shrinkage and setting time tests. The results indicated that the inclusion of cement on to juss increases the compressive strength, absorption percentage, density, acoustic impedance, ultra - pulse velocity, longitudinal shrinkage and a reduction in flexural strength and setting time were observed by adding the cement. In addition, the inclusion of polypropylene fiber was significant in improving mechanical performance of the composite material, it shows a great improvement in longitudinal shrinkage, modulus of rupture and absorption percentages.
\end{abstract}

Index Terms - modified juss, compressive strength, flexural strengths, absorption percentage, density, acoustic impedance, longitudinal shrinkage

\section{Introduction}

Plaster is a very cheap building material, it's used since ancient time. Plaster has a lot of applications such as fire proofing plasterboard and decoration. The only most important factor likely to affect the strength of the gypsum binder is the water. The existence of atmospheric moisture even at low relative humidity is enough for bring about a significant reduction in strength of gypsum binder. For this reason, gypsum products are used in the building industry as a surface finish on interior walls.

Many studies have been carried out to enhance the mechanical strength of the plaster Dalmay, et al., [1] presented a study about the use of different natural fibers namely (flax and hemp) to enhance the mechanical properties of plaster. Results showed that the behavior of composite matrix was modified from brittle to a nonlinear one. Moreover, even a small addition of fibers enhance the flexural strength. The result also showed that when fibers were added to the plaster, hemp fibers delayed the setting time as compared to flax fibers. Research by Carvalho, et al.,[2] showed that calluses pulp fibers improved the modulus of rupture compared to gypsum paste without calluses pulp fibers. Coalk, [3] used a mixture of Portland cement -natural pozzolana to study its impact on density, strength development and durability of gypsum. The result showed that an increase in the density and strength development of gypsum Portland cement and gypsum - Portland cement pozzolana compared to gypsum only. Moreover, the density and strength development, decreases with increase in the percentage of natural pozzolana they also concluded that natural pozzolana can be effective in improving the resistance of gypsum-Portland cement blends to water. Some other researchers show different results from Coalk, [3] Bentur, et al., [4] reported that Mixing of Portland cement and gypsum is usually infeasible because it can result in the formation of ettringite, which leads to deterioration. A combination of Portland cement and silica fume, may provide conditions to eliminate the formation of ettringite, and perhaps make it feasible to produce a gypsum-Portland cementpozzolana blend which owns the advantages of both gypsum and Portland cement, but the researchers also reported that increasing the percentage of pozzolana material can be effective in improving the strength of gypsum. Gencel, et al., [5] used two additives [expanded vermiculite and polypropylene fibers] to improve the physical and mechanical properties of the gypsum. The gypsum composite was analyzed based on unit weights and compressive strength. They reported that the pp

Corresponding author: Naljalawi@yahoo.com 
fibers enhanced the mechanical properties, while, both expanded vermiculite and the fibers reduced the unit weight of the gypsum composites. Abdulhussein, [6] used resole resin to improve the properties of local Iraqi gypsum. The prepared composites of elasticity. On the other hand a reduction in bending strength and swelling $\%$ were observed when the proportion of resole resin in gypsum composite was increased. Al -Ubaidi,[7] and Frieh, et al.,[8] prepared different gypsum composite samples to improve the Iraqi gypsum. Hydrated lime, limestone, metakaoline and kaoline were used in this work. The result shows that the setting time and the compressive strength increased by using hydrated lime and limestone while the compressive strength decreases for some weight percent of adding by $19 \%$ and $13.6 \%$ for metakaoline and kaoline respectively, in addition, the modulus of rapture decreased by adding these admixtures. Sern, et al., [9] used different forms and percentages of waste rubber to improve the elastic behavior of gypsum. The result indicated that the addition of waste rubber particles lead to decreases in bending and compressive strength and increases in elastic modulus, they also reported that a reduction in toughness was observed and this may cause a worse behavior in crack resistance. In the present work gypsum composites containing cement and cement polypropylene fibers were prepared to examine their physical and mechanical properties.

\section{Research significant}

Synthetic fibers are already used in different types of materials like concrete, plastics and lime-based products. They show different features like the combination of good mechanical, acoustic and thermal properties that allow these types of materials to be used for different applications. The main defect associated with juss is its brittleness, especially under tensile stress. Therefore, it is interesting to investigate different methods that could enhance the mechanical properties of juss. Adding fibres and cement to obtain a composite material is one way to improve the behaviour of the product, especially after the failure of the matrix. The aim of this work was to the study the effects of adding synthetic fibers, namely polypropylene, on the setting time and the mechanical properties of the composite matrix.

\section{Materials}

\subsection{Local juss}

A local Iraqi juss was used in this study. The consistency and the setting time were measured following the IQS NO. 27, [10] and IQS NO.28, [11] standard, respectively. Table 1 illustrates the property of this juss.
Table 1.

The chemical and physical properties for the various binders

\begin{tabular}{|c|c|c|}
\hline Oxide & Cement & Juss \\
\hline $\mathrm{CaO}$ & 62.96 & \\
\hline $\mathrm{SiO}_{2}$ & 20.51 & 27.48 \\
\hline $\mathrm{Fe}_{2} \mathrm{O}_{3}$ & 2.96 & 0.59 \\
\hline $\mathrm{Al}_{2} \mathrm{O}_{3}$ & 5.57 & 6.65 \\
\hline $\mathrm{MgO}$ & 2.35 & 0.8 \\
\hline $\mathrm{SO}_{3}$ & 1.9 & 34.75 \\
\hline $\begin{array}{c}\text { Loss on agent } \\
\text { L.O.I\% }\end{array}$ & 0.93 & 7.25 \\
\hline $\mathrm{I} . \mathrm{R} \%$ & 0.83 & \\
\hline L.S.F & 0.93 & \\
\hline Fineness (m & \\
\hline $\begin{array}{c}\text { Vicat set (hr:min) } \\
\text { Initial }\end{array}$ & 3.817 & \\
Final & $3: 00<10$ & \\
\hline $\begin{array}{c}\text { Mortar Compressive } \\
\text { Strength ( N/mm } \\
\text { at }\end{array}$ & & \\
at & $30>15$ & \\
3 days & $32>23$ & \\
7 days & & \\
\hline
\end{tabular}

\subsection{Cement}

The used cement was ordinary Portland cement Type (1), which conformed to IQS No. 5[12]. Table 1 shows the properties of this cement.

\subsection{Polypropylene fibers $p p$}

Crimped Polypropylene fibers (pp) with $(30 \mathrm{~mm})$ length, $(0.47 \mathrm{~mm})$ diameters and Specific gravity of 1.1 were used.

\section{Experimental work}

\subsection{Modified juss}

The modified juss was prepared by adding two percentages of cement $(5,10) \%$ to the local Iraqi juss. For preparing modified juss reinforced with $(1,2) \%$ of pp fiber, the dry compounds (fibers, cement and juss) were first mixed by hand until the fibers were coated with cement and juss. Then, the dry mix was slowly added to water and mixed for a proper time by hand. The water/dry compound ratio used was equal to 0.53 to ensure a sufficient fluidity even for the highest percentages of fibers. The mix is then poured into moulds and compacted by thin rod. Table 2 shows the details of juss mixes, local Iraqi juss was used in this study. The consistency and the setting time were measured following the IQS. 
Table 2. Set and description of mixes

\begin{tabular}{|c|c|}
\hline Mix notation & Descriptions of mixes \\
\hline $\mathrm{G}$ & reference juss \\
\hline GC5 & juss blended with $5 \%$ cement \\
\hline $\mathrm{GC} 10$ & Juss blended with $10 \%$ cement \\
\hline GF2 & juss blended with $2 \%$ pp fibers \\
\hline GC5F1 & $\begin{array}{c}\text { juss blended with } 5 \% \text { cement and } 1 \% \text { pp } \\
\text { fibers }\end{array}$ \\
\hline GC5F2 & $\begin{array}{c}\text { juss blended with } 5 \% \text { cement and } 2 \% \text { pp } \\
\text { fibers }\end{array}$ \\
\hline GC10F1 & $\begin{array}{c}\text { juss blended with } 10 \% \text { cement and } 1 \% \text { pp } \\
\text { fibers }\end{array}$ \\
\hline
\end{tabular}

\section{Result and Discussion}

\subsection{Setting Times}

The setting time of the gypsum and the gypsum composite samples were measured following the Iraq standard NO.28,[11]. Table 3 shows the result of the setting time

Table 3 Setting time of juss specimens

\begin{tabular}{|c|c|}
\hline Mix notation & $\begin{array}{c}\text { Setting Time } \\
\text { min }\end{array}$ \\
\hline G & $12: 30$ \\
\hline GC5 & $10: 35$ \\
\hline GC10 & $8: 55$ \\
\hline GF2 & $10: 20$ \\
\hline GC5F1 & $10: 25$ \\
\hline GC10F1 & $8: 40$ \\
\hline GC5F2 & 10 \\
\hline GC10F2 & 8 \\
\hline & \\
\hline
\end{tabular}

It was shown that with constant water/dry compound, the setting times of both composites made with cement and pp fibers were reduced by about $(16,30,17,16.6,31,19$, and 35$) \%$ for GC5, GC10, GF2, GC5F1, GC10F1, GC5F2 and GC10F2, respectively comparable with $(G)$, as shown in Fig 1. This may be due to the reduction in water content because it is already consumed by the cement paste during continuous hydration, as a result, setting times is reduced

In all cases, the setting times of both composites made with cement and pp fiber mixtures conformed to the Iraqi specifications.

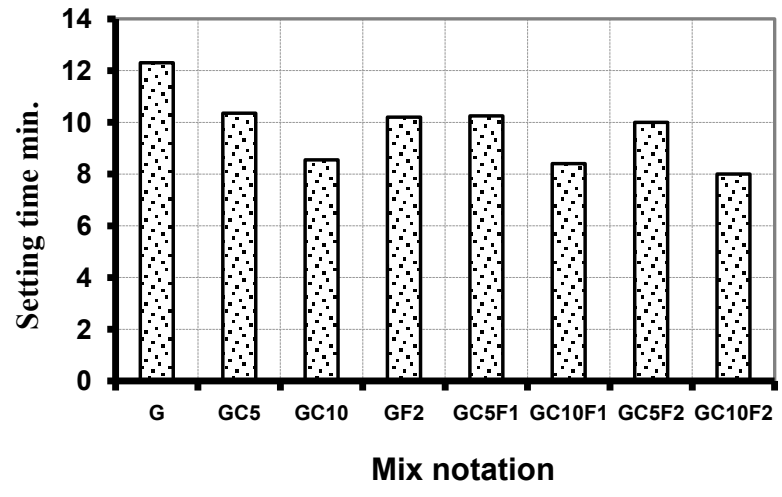

Fig. 1. Setting time of juss samples

\subsection{Compressive Strength}

The compressive strengths of the gypsum and the gypsum composite samples were measured following the ASTM C472-99 [13] standard. Table 4 shows the result of the compressive strength. The results show that the composite made with a matrix of juss and cement, had a compressive strength higher than for composite made with a matrix of juss, cement and pp fibers. The increase of the compressive strength indicate good adhesion matrix of juss and cement. The increase for mixes was $(15.5,37.3,6,25,1$ and 20$) \%$ for GC5, GC10, GC5F1, GC10F1, GC5F2 and GC10F2, respectively, comparable with reference $\mathrm{G}$.

The results also show that the composite made with a matrix of juss and $2 \%$ pp fibers (GF2\%) has a lower compressive strength as shown in Fig 2 comparable with (G). This may be attributed to the presence of voids, where the addition of fibers may increase the voids in juss sample.

Table 4. Compressive strength and modules of rupture of juss specimens.

\begin{tabular}{|c|c|c|}
\hline $\begin{array}{c}\text { Mix } \\
\text { notation }\end{array}$ & $\begin{array}{c}\text { Compressive } \\
\text { strength }\left(\mathrm{N} / \mathrm{mm}^{2}\right) \\
\text { 14 DAYS }\end{array}$ & $\begin{array}{c}\text { Modules of rupture } \\
\left(\mathrm{N} / \mathrm{mm}^{2}\right) \\
14 \text { days }\end{array}$ \\
\hline G & 4.95 & 4.3 \\
\hline GC5 & 5.72 & 3.6 \\
\hline GC10 & 6.8 & 3.3 \\
\hline GF2 & 4.23 & 10.9 \\
\hline GC5F1 & 5.25 & 5.1 \\
\hline GC10F1 & 6.2 & 4.9 \\
\hline GC5F2 & 5 & 7.2 \\
\hline GC10F2 & 5.94 & 6.9 \\
\hline & & \\
\hline
\end{tabular}




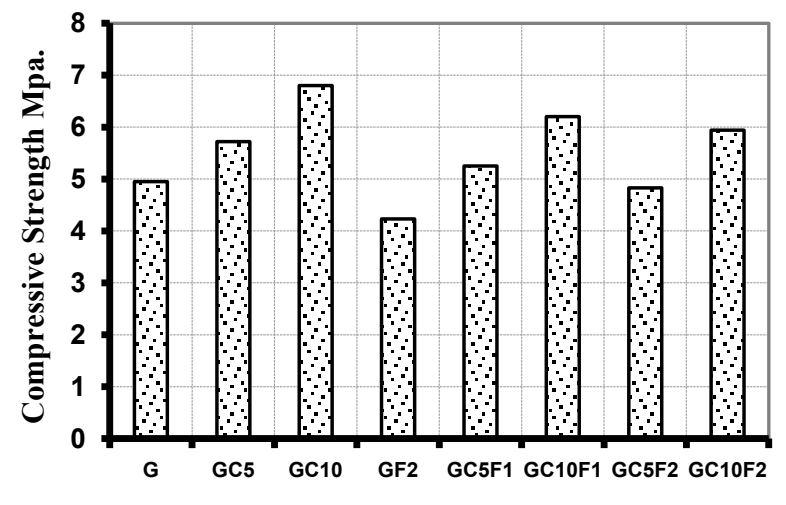

Mix notation

Fig. 2. Compressive strengths of juss samples

\subsection{Modulus of Rupture test}

The samples were analyzed based on modulus of rupture tests with three -point loading, following the recommendations of the ASTM C293-02 [14]. Table 4 and Fig. 3 show the results of modulus of rupture for juss samples. The addition of pp fibers causes an increase in modulus of rupture by $(153,18.6,13.9,67.4,60.4) \%$ for GF2, GC5F1, GC10F1, GC5F2 and GC10F2, respectively compared to $(\mathrm{G})$. The increase in modulus of rupture for GF2 samples is very significant as shown in Fig.3. This increase may be due to the high tensile strength of the pp fibers which tries to arrest the micro cracks that occur under increased loads. On the other hand, the addition of cement causes a decrease in modulus of rupture by (16 and 23 )\% for GC5 and GC10, respectively. This may be attributed to the following:

1. In the case of the compressive strength tests, the formation of ettringite which can form stress as a result of the interaction between the cement and juss, as reported by Bentur, et al., [4] was less pronounced and this may due to the low percentage of cement.

In the case of modulus of rupture tests the forms of stresses may increase the deflection and as a result, reduce the modulus of ruptures value.

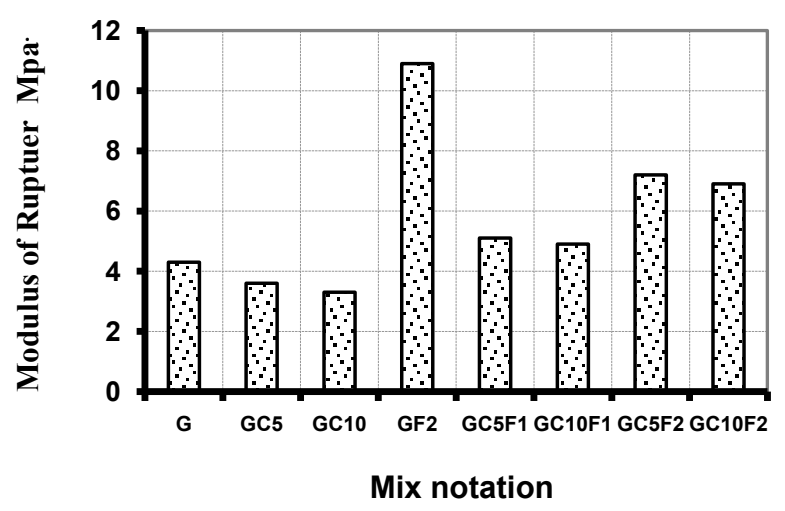

Fig. 3. Modulus of rupture of juss samples.

\subsection{Absorption test}

The Table 5 and Fig. 4 show the results of absorption tests for juss samples. The addition of cement causes an increase in absorption by (4 and 9)\% for GC5 and GC10, respectively compared to $(\mathrm{G})$. This increase may be due to the absorption of cement paste during the hydration process thus increasing the absorption \%. While the addition of pp fibers reduce the absorption percentage for gypsum samples. This may be due to the water proof property of $\mathrm{pp}$.

Table 5. Absorption and longitudinal shrinkage percentages of juss specimens

\begin{tabular}{|c|c|c|}
\hline $\begin{array}{c}\text { Mix } \\
\text { notation }\end{array}$ & $\begin{array}{c}\text { Absorption } \\
\%\end{array}$ & $\begin{array}{c}\text { Longitudinal Shrinkage } \\
\%\end{array}$ \\
\hline G & 0.23 & 2 \\
\hline GC5 & 0.24 & 2 \\
\hline GC10 & 0.25 & 3 \\
\hline GF2 & 0.2 & 0.8 \\
\hline GC5F1 & 0.2 & 1.4 \\
\hline GC10F1 & 0.22 & 1.9 \\
\hline GC5F2 & 0.22 & 1 \\
\hline GC10F2 & 0.23 & 1.6 \\
\hline & & \\
\hline
\end{tabular}

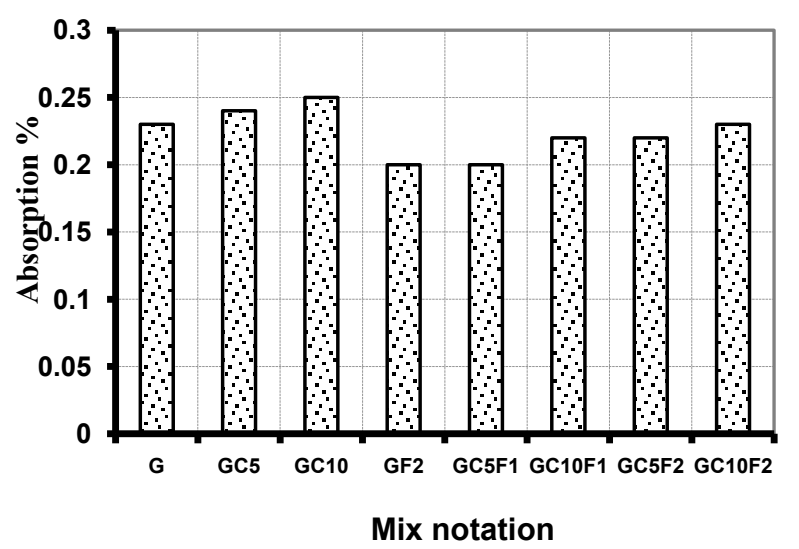

Fig. 4. Absorption percentage of juss samples

\subsection{Longitudinal shrinkage}

Table 5 and Fig. 5 show the results of longitudinal shrinkage for juss samples. The addition of pp fibers causes a decreases in longitudinal shrinkage by $(60,30$, $50,5,50$ and 20) for GF2, GC5F1, GC10F1, GC5F2 and GC10F2, respectively compared to $(\mathrm{G})$. Using pp fibers can be effective in retaining the cementitous matrix integrity and reducing the Longitudinal Shrinkage which can occur after the hydration of cement paste. On the other hand, the addition of cement $(10) \%$ causes an increase in longitudinal shrinkage by $(50 \%)$ for $\mathrm{GC} 10$, this may be attributed to reduce in water content because it is already consumed by the cement paste during 
continuous hydration, consequently, longitudinal shrinkage is increased.

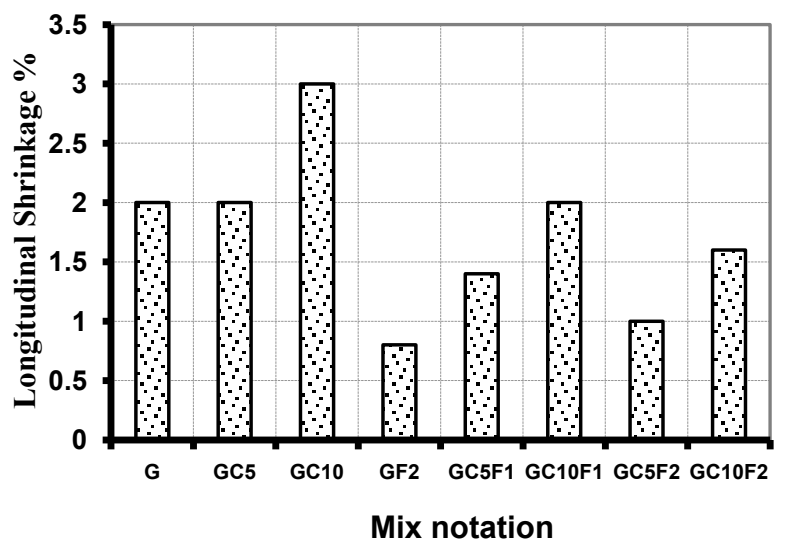

Fig. 5. Longitudinal shrinkage percentage of juss samples

\subsection{Density test}

Table 6 and Fig. 6 shows the results of density tests for juss samples. A general increase in the density of jussPortland cement blends is observed compared to reference Juss. The increase_for mixes was $(21,24,20$, 29, 24 and 31) \% for GC5, GC10, GC5F1, GC10F1, GC5F2 and GC10F2, respectively, compared to reference $\mathrm{G}$. This result indicates that a uniform density can be obtained for juss -Portland cement blends. This finding is supported by Coalk, [4]. The results show that the composite made with a matrix of Juss, cement and a reinforcing $p p$ fibers, had a density higher than for composite made with a matrix of Juss and cement only. The increase of the density indicates good adhesion matrix of Juss, cement and pp fibers. On the other hand GF2\% (with juss and 2\% pp fibers) has a slight loss of density. This may be due to the low density of PP fibers.

Table 6. Density, ultra - pulse velocity And acoustic impedance of juss specimens

\begin{tabular}{|c|c|c|c|}
\hline $\begin{array}{c}\text { Mix } \\
\text { notation }\end{array}$ & $\begin{array}{c}\text { Density } \\
\mathrm{kg} / \mathrm{m}^{3}\end{array}$ & $\begin{array}{c}\text { Ultra - pulse } \\
\text { velocity } \\
\mathrm{Km} / \mathrm{sec}\end{array}$ & $\begin{array}{c}\text { Acoustic } \\
\text { Impedance } \\
\mathrm{kg} / \mathrm{s}^{2} \mathrm{~m}^{2}\end{array}$ \\
\hline $\mathrm{G}$ & 1.11 & 1.5 & 1.66 \\
\hline GC5 & 1.34 & 1.54 & 2.1 \\
\hline GC10 & 1.38 & 1.64 & 2.26 \\
\hline GF2 & 1.08 & 1.26 & 1.6 \\
\hline GC5F1 & 1.33 & 1.66 & 2.21 \\
\hline GC10F1 & 1.43 & 1.8 & 2.57 \\
\hline GC5F2 & 1.38 & 1.76 & 2.42 \\
\hline GC10F2 & 1.45 & 1.82 & 2.63 \\
\hline
\end{tabular}

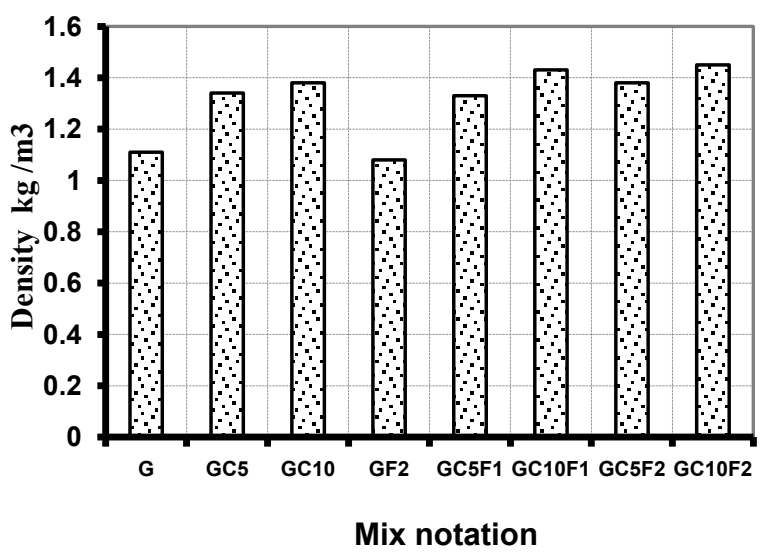

Fig.6. Density of juss samples

\subsection{Ultra - pulse velocity test}

The samples followed the recommendations of the ASTM C597-02[15]. Table 6 and Fig.7 show the results of ultra - pulse velocity tests for juss samples. It appears that the Ultra - pulse velocity value increases with the addition of cement and PP fibers compared to reference juss. The increase for mixes was $(3,9,11,20,17$ and 21) for GC5, GC10, GC5F1, GC10F1, GC5F2 and GC10F2 respectively, comparable with reference $\mathrm{G}$. This may be due to the increases in specimen density and reduction voids and discontinuity point. On the other hand GF2\% (with juss and $2 \%$ pp fibers) has a slight reduction in ultrasound velocity wave, the reason of this anomaly may be due to the fact that pp fibers are good acoustic insulator, so they act as obstacles to disperse waves.

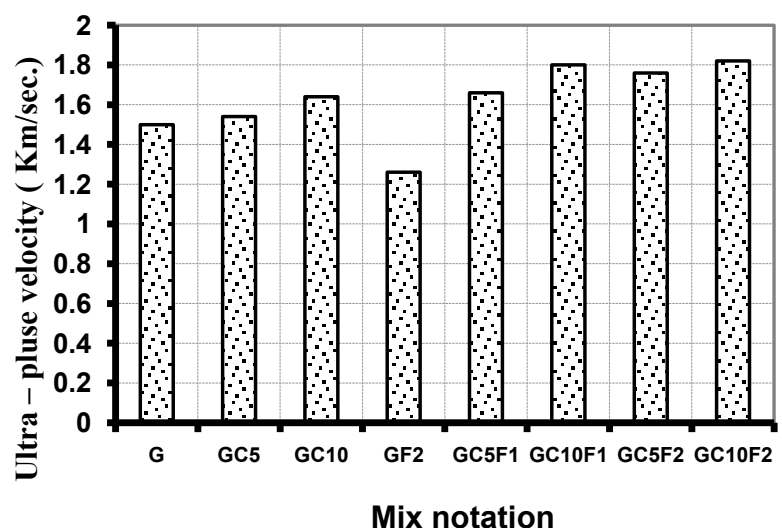

Fig 7. Ultra - pulse velocity of juss samples 


\subsection{Acoustic impedance test}

The acoustic impedance test of the gypsum and the gypsum composite samples were measured as per the following equation [16]

Acoustic Impedance test $=$ velocity $\times$ density

Table 6 and Fig. 8 show the results of acoustic impedance tests for juss samples. It appears that the acoustic impedance value increases with the addition of cement compared to reference juss. The increase for mixes was $(27,36,33,55,46$ and 58$) \%$ for GC5, GC10, GC5F1, GC10F1, GC10F2 and GC5F2, respectively, compared to reference $\mathrm{G}$. This may be due to the increases in specimen density and reduction voids and discontinuity point.

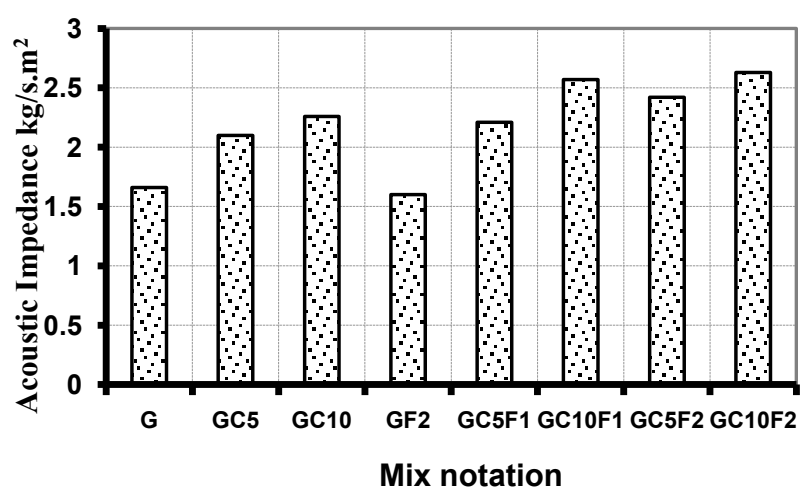

Fig 8. Acoustic impedance of juss samples

On the other hand GF2\% (with juss and 2\% pp fibers) has a slight reduction in acoustic impedance, the reason of this anomaly may be due to decreases in specimen density

\section{Conclusion}

The findings from this study are summarized as follows:

1. The density of juss-Portland cement-pp fiber blends ranges from about 1.35 to $1.45 \mathrm{~kg} / \mathrm{m}^{3}$. Density variations are usually caused by the changes in mix proportion. Lower densities can be obtained by increasing the juss or reducing the cement content in the mix. In addition, the use of pp fibers only in juss mixtures, led to a decreases in density by (3)\% lower than reference mixes.

2. The Acoustic Impedance value and the Ultra pluse velocity increase with the addition of both cement and pp fibers. On the other hand, a decrease in Acoustic Impedance value and Ultra - pluse velocity in mixes using pp fibers only, by (3.6 and 20$) \%$, respectively lower than reference mixes.

3. pp fibers $(2) \%$ are effective in reducing the longitudinal shrinkage and absorption percentages. While adding $5 \%$ to $10 \%$ Portland cement by weight of binder dramatically increases the longitudinal shrinkage and absorption percentages when compared to paste without Portland cement.

4. pp fibers and Portland cement were found to accelerate the setting time of juss when the water/dry compound was constant, comparable with reference juss and in all cases, the setting time of the composite material conformed to the Iraqi specification criteria.

5. The addition of pp fibers causes an increase in modulus of rupture while the addition of cement causes a decrease in modulus of rupture comparable with reference juss.

6. A blend of juss and a mixture of Portland cement and pp fibers can provide a system with strength levels higher than those of juss only.

\section{References}

1. P. Dalmay, A. Smith, T. Chotard, P. S. Turner, V. Gloaguen, and P. Krausz, Journal of Materials Science Vol. 45, PP.793-803,( 2010)

2. M. A. Carvalhoa, C. C. Júniora, H. S. Juniorb, R.Tubinoc,, and M. T. Carvalhod, Materials Research, Vol. 11, No. 4, PP. 391-397, (2008)

3. A. Colak, Cement and Concrete Research, Vol. 32, PP. 109- 115, (2002)

4. A. Bentur, K. Kovler, and A. Goldman, Advances in Cement Research, Vol. 6, No. 23, PP. 109-116,( 1994)

5. O. Gencel, J. J. Diaz, M. Sutcu, F. Koksal, F.P.A Rabanal, G. M. Barrerae, and W. Brostow, Energy and Buildings , Vol.70 , PP. 135-144,( 2014)

6. A. A. Abdulhussein, Journal of Kerbala University , Vol. 10, No.2, PP. 211-220. (2012)

7. L. S. Al-Ubaidi, MSc, University of Technology, PP.1-98 .( 2004)

8. k. J. Frieh, W. A. AL -Qasi, and L. S. Al-Ubaidi, Eng .\&Tech. Journal,Vol.24, No .9, PP. 380 -393,( 2005)

9. A. Sern, M. Rio, J. G. Palomo,.., and M. Gonzalez, Construction and Building Materials, Vol. 35, PP. 633-641, (2012)

10. Iraqi Specification, , Physical examinations of juss for construction, Central Organization for Standardization and Quality Control No. 27 , (1988) 
11. Iraqi Specification, No. 28, juss for construction, Central Organization for Standardization and Quality Control (2010)

12. Iraqi Specification, No. 5, "Portland cement"(1984).

13. ASTM C472-99 Standard Test Methods for Physical Testing of Gypsum, Gypsum Plasters and Gypsum Concrete (1999)

14. ASTM C293-02, Standard test method for flexural strength of concrete (using simple beam with centerpoint loading), Annual Book of ASTM Standard, Vol. 04-02,. .(2002)

15. ASTM C597-02, Standard test method for pulse velocity through concrete, Annual Book of ASTM Standard, Vol. 04-02 .(2002)

16. E. K. Lawrence, $4^{\text {th }}$ edition ,John Wiley \& Sons Inc, ( 2000) 